\title{
Effectiveness and Safety of Dietetic Supplementation of a New Nutraceutical on Lipid Profile and Serum Inflammation Biomarkers in Hypercholesterolemic Patients
}

\author{
Graziano Riccioni ${ }^{1, *}$, Maria Alessandra Gammone ${ }^{2}$, Walter Currenti ${ }^{3}$ and \\ Nicolantonio D'Orazio ${ }^{3}$ \\ 1 Cardiology Unit, San Camillo de Lellis Hospital, Manfredonia, Foggia 71100, Italy \\ 2 Human Nutrition, “G. D’Annunzio” University, Chieti-Pescara 66013, Italy; \\ m.alessandra.gammone@gmail.com \\ 3 Department of Biomedical and Biotechnological Science, School of Medicine, University of Catania, \\ Catania 95100, Italy; walter.currenti@unich.it (W.C.); ndorazio@unich.it (N.D.) \\ * Correspondence: grazianoriccioni@gmail.com; Tel.: +39-333-636-6661; Fax: +39-0882-227022
}

Academic Editor: Fabio Galvano

Received: 18 January 2018; Accepted: 25 April 2018; Published: 14 May 2018

\begin{abstract}
Background: To assess the effectiveness and safety of a new nutraceutical (NC) on lipid profile, inflammation biomarkers and creatine phosphokinase (CPK) serum levels in hypercholesterolemic patients. Methods: 40 patients underwent hypolipemic treatment with NC. Initial and final (after 12 weeks) screening included medical history, physical examination, and measurement of serum lipid profile (total cholesterol, HDL-cholesterol, LDL-cholesterol, and triglycerides), hepatic (GOT, GPT, $\gamma \mathrm{GT}$ ), and renal (serum creatinine and urea) functions, CPK level and many inflammation biomarkers (hs-CRP and fibrinogen). At the screening visit, all patients were instructed to follow a normocaloric and hypolipidic diet during the study period. Results: The treatment with supplementation of NC demonstrated a significant reduction of serum total cholesterol (224 $\pm 11.2 \mathrm{mg} / \mathrm{dL}$ vs. $178 \pm 10.7 ; p<0.001)$, LDL-cholesterol $(141 \pm 10.6$ vs. $116+10.1$; $p<0.001)$, triglycerides (183 \pm 13 vs. $159 \pm 11.5 ; p<0.01)$, serum inflammatory biomarkers as hs-CRP $(2.24 \pm 0.83$ vs. $1.76 \pm 0.61 \mathrm{mg} / \mathrm{dL} ; p<0.01)$, fibrinogen $(315 \pm 43$ vs. $199 \pm 41 \mathrm{mg} / \mathrm{dL} ; p<0.01)$ and a significantly increase of HDL-cholesterol ( $44 \pm 7$ vs. $53 \pm 7 \mathrm{mg} / \mathrm{dL} ; p<0.01)$. Hepatic and renal function and serum CPK were normal. No adverse events was reported. Conclusions: The treatment with NC has demonstrated a significant reduction of LDL-cholesterol $(-17.73 \%)$, total cholesterol $(-20.53 \%)$ and triglycerides $(-13.1 \%)$, with a significant increase of HDL-cholesterol values $(+20.45 \%)$. The improvement of lipid profile was associated with a significant reduction of serum inflammation biomarkers as hs-PCR $(-27 \%)$ and fibrinogen $(-36.8 \%)$ with good tolerability profile.
\end{abstract}

Keywords: berberine; red yeast rice; monacolin K; resveratrol; lycopene; cholesterol; triglycerides; hypercholesterolemia; hydroxytyrosol; zinc

\section{Introduction}

Cardiovascular diseases (CVD) represent one of the most important cause of mortality and morbidity in the industrialized world [1,2]. The atherosclerotic process is an important pathogenetic factor of CVD; in particular, hypercholesterolemia is one of most important risk factors that contribute to the formation and progression of atherosclerotic plaque secondary to elevated levels of low density lipoprotein cholesterol (LDL-C), that initially determine an endothelial dysfunction, an early step in 
CVD that contributes to plaque initiation and formation [3]. All CVD prevention guidelines recommend the use of statins to lower lipid levels although one third of statin users discontinue this therapy within one year from beginning. One of the reason of this non-adherence is represented to intolerance [4]. The recommended target level for total cholesterol (TOT-C) is less than $190 \mathrm{mg} / \mathrm{dL}$ in all patients, whereas the recommended level of LDL-C varies according to European Society of Cardiology/European Atherosclerosis Society (ESC/EAS) guidelines as follow: less than $115 \mathrm{mg} / \mathrm{dL}$ in subjects at moderate risk ( $\geq 1 \leq 5 \%$ ); less than $100 \mathrm{mg} / \mathrm{dL}$ in subjects at high risk ( $\geq 5 \leq 10 \%$ ); less than $70 \mathrm{mg} / \mathrm{dL}$ in subjects at very high total cardiovascular risk $(\geq 10 \%)$. These targets should be achieved primarily by lifestyle changes represented to reduction in dietary sutured fat, use of functional foods enrich with phytosterols, reduction in excessive body weight and increase in habitual physical activity [5]. An alternative therapy included in the guidelines is the use of innovative nutritional strategies, based on consumption of specifically targeted "health" functional foods and/or dietary supplements-the so-called nutraceuticals - which can be used, together with dietary measurements, in alternatives or addition to lipid-lowering drugs so as not to have to increase their dose. The ESC/EAS guidelines mention phytosterols, soy, dietary fiber, policosanol, red yeast rice and berberine [5].

Aim of our study is to assess the effectiveness and safety of a dietetic supplementation of a new nutraceutical combination (NC) [berberine, red yeast rice (RYR) and monacolin K, policosanol, folic acid, coenzyme $\mathrm{Q}_{10}\left(\mathrm{CoQ}_{10}\right)$, asthaxantin, resveratrol, vitamin $\mathrm{E}$, hydroxytyrosol, lycopene, and zinc] on lipid profile (TOT-C, HDL-C, and LDL-C, triglycerides), many inflammation biomarkers (hs-CRP, fibrinogen) and creatine phosphokinase (CPK) serum levels in patients with hypercholesterolemia.

\section{Methods and Statistical Analysis}

We enrolled 40 hypercholesterolemic patients (20 males, 20 females; $41 \pm 7$ years mean age; BMI $29.2 \pm 1.3$ ), non- smokers, who underwent hypolipemic treatment with NC (berberine [600 mg], RYR [200 mg], monacolin K [3 mg], policosanol [100 mg], folic acid [200 mcg], CoQ 10 [50 mg], asthaxantin [0.5 mg], resveratrol [20 mg], hydroxytyrosol [20 mg], vitamin E [12 mg], lycopene [20 mg], and zinc [10 $\mathrm{mg}])$.

Initial and final (after 12 weeks) screening included medical history, physical examination, and measurement of serum lipid profile (TOT-C, HDL-C, LDL-C, and TG), hepatic (GOT, GPT, $\gamma$ GT), and renal (serum creatinine and urea) functions, CPK levels and many inflammation biomarkers (hs-CRP and fibrinogen). At the screening visit, all patients were instructed to follow a normocaloric and hypolipidic diet during the study period. Were excluded to the study patients with intolerance to NC compounds, with renal and hepatic diseases, pregnant women, and patients treated with lipid-lowering drugs or substances. Adverse events were monitored throughout the study. All patients had to provide a written informed consent.

Data are presented as mean \pm SD. The effect of treatment was analyzed by comparing the absolute changes from baseline values by means of $t$-Student test. Data were analyzed by using SPSS statistical software (SPSS Inc., Chicago, IL, USA).

\section{Results}

After 12 treatment weeks the comparison of changes respect to baseline values showed a significant reduction of TOT-C $(224 \pm 11.2 \mathrm{mg} / \mathrm{dL}$ vs. $178 \pm 10.7 ; p<0.001), \mathrm{LDL}-\mathrm{C}(141 \pm 10.6 \mathrm{mg} / \mathrm{dL}$ vs. $116+10.1 \mathrm{mg} / \mathrm{dL} ; p<0.001)$, TG $(183 \pm 13 \mathrm{mg} / \mathrm{dL}$ vs. $159 \pm 11.5 \mathrm{mg} / \mathrm{dL} ; p<0.01)$ (see Figure 1), serum inflammatory biomarkers as hs-CRP $(2.24 \pm 0.83 \mathrm{mg} / \mathrm{dL}$ vs. $1.76 \pm 0.61 \mathrm{mg} / \mathrm{dL} ; p<0.01)$, fibrinogen (315 $\pm 43 \mathrm{mg} / \mathrm{dL}$ vs. $199 \pm 41 \mathrm{mg} / \mathrm{dL} ; p<0.01)$ and a significantly increase of HDL-C (44 $\pm 7 \mathrm{mg} / \mathrm{dL}$ vs. $53 \pm 7 \mathrm{mg} / \mathrm{dL} ; p<0.01)$ (see Figure 1). Hepatic and renal function and serum CPK were normal (see Table 1). No adverse events was reported. 


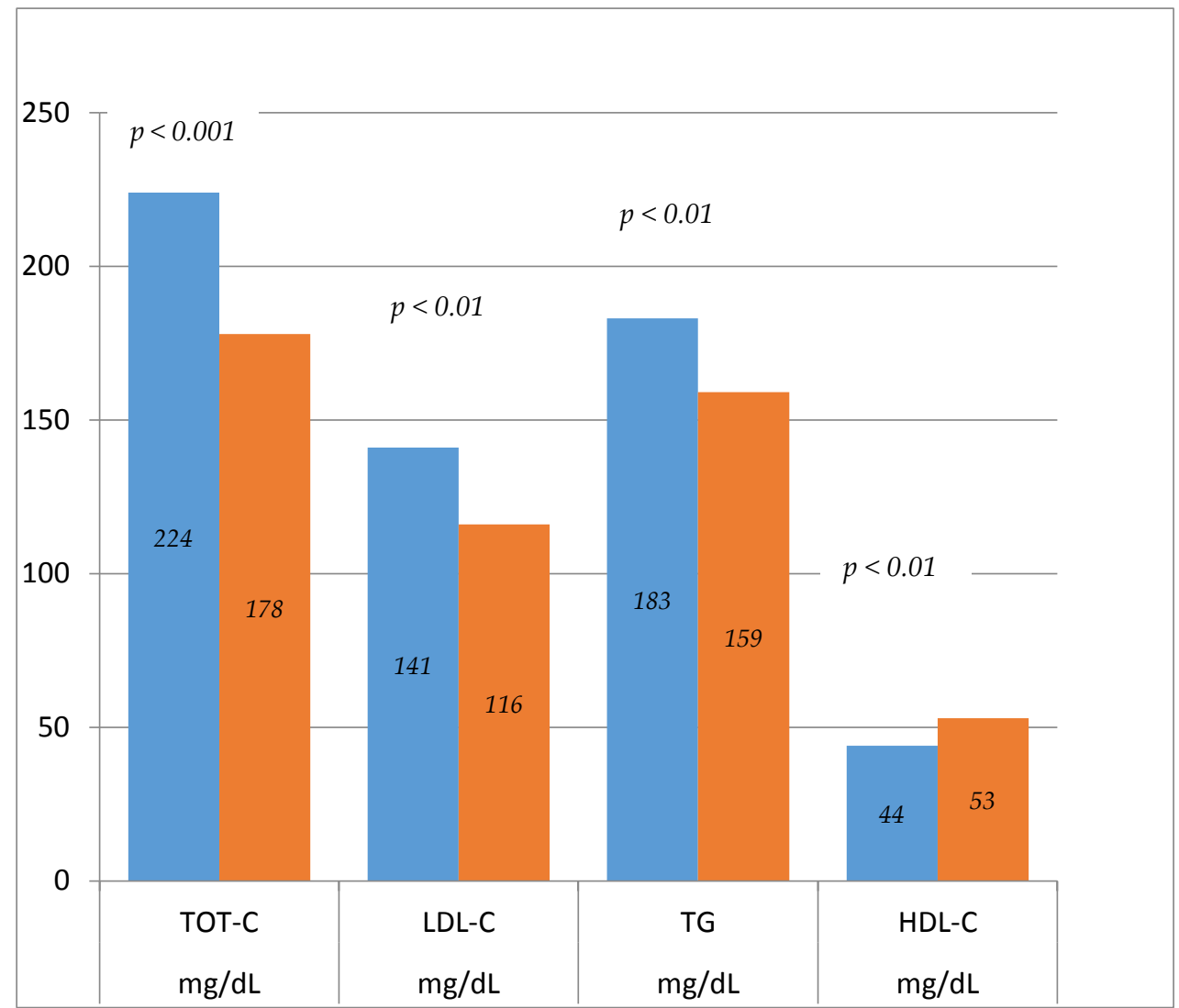

Figure 1. Lipid profile (pre-post treatment).

Table 1. Safety profile.

\begin{tabular}{ccc}
\hline & T0 Pre-Treatment & T12 Post-Treatment \\
\hline GOT (UI/L) & 28 & 29 \\
GPT (UI/L) & 31 & 30 \\
GGT (UI/L) & 27 & 25 \\
CPK (UI/L) & 195 & 189 \\
Crea (mg/dL) & 0.97 & 0.94 \\
Urea (mg/dL) & 47 & 39 \\
\hline
\end{tabular}

\section{Discussion}

This study demonstrated that 12 weeks of treatment with a new NC significantly reduced TOT-C, LDL-C and TG values in subjects with mild-moderate hypercholesterolemia. This result was associated with a significant increase of HDL-C values and a significant reduction of inflammatory biomarkers (hs-CRP and fibrinogen). No adverse events were observed during the study period.

The effects showed in the study are due to the important effects of NC. In particular RYR with monacolin $\mathrm{K}(3 \mathrm{mg})$ modulate the lipid profile by reducing TOT-C and LDL-C via "statin like mechanism" i.e., by competitively inhibiting HMG-CoA reductase [6]; the presence of monacolin $\mathrm{K}$ improve the affinity of this enzyme for the endogenous substrate [7].

Berberine, a natural alkaloid, may reduce expression of proprotein convertase subtilisin/kexin type 9 (PCSK9), and consequently lower LDL-C receptor degradation and increase liver low density lipoprotein receptor (LDL-R) expression with stimulation of hepatic uptake of plasma cholesterol, thus promoting clearance of LDL-C from the bloodstream [8]. Interestingly the mechanism of efficacy of berberine is independent to intracellular cholesterol plasma levels and is not diminished by 
other cholesterol-lowering substances. Additionally berberine reduces macrophage migration [9], and induced the expression of cholesterol efflux gene ATP-binding cassette transporter 1 (ABCA1), resulting in reduced intravascular accumulation of oxidized-LDL (ox-LDL) in human macrophages [10]. All these effects of berberine have been demonstrated in several randomized placebo-controlled trials involving patients with mild to moderate mixed hyperlipidemia, with or without type 2 diabetes mellitus and hyperlipemic patients with $\mathrm{B}$ or $\mathrm{C}$ cirrhosis. These studies have documented a significant reduction in LDL-C values (20-25\%) and triglycerides (13-30\%) [11].

$\mathrm{CoQ}_{10}$, an antioxidant present in many food sources, has an important role in the electron transport chain with the mitochondria. Given that $\mathrm{CoQ}_{10}$ and cholesterol synthesis share the same intermediate steps in their respective biosynthetic pathways, patients receiving statin treatment also experience a reduction in $\mathrm{CoQ}_{10}$ [12]. In addition, $\mathrm{CoQ}_{10}$ is essential for oxide reduction involved in ATP synthesis, prevent LDL peroxidation and represent one of the main antioxidant defenses of the human body involved [13].

Resveratrol (RES) is a natural phenol commonly found in the skin of grapes and is considered to be one of the key active compounds responsible for these cardiovascular protective effects. These effects are due to reduction of foam cells formation by inhibiting ox-LDL uptake as well as increasing cholesterol efflux in human THP-1 macrophages [14]. Several studies have found that higher average alcohol consumption (wine) reduce the incidence of CVD [15], CVD-event and all-cause mortality [16].

Lycopene is the carotenoid that gives tomatoes their bright red colour. These substance inhibits LDL oxidation in vitro [17] and might exert its anti-atherogenic effects by inhibiting de novo cholesterol synthesis. Several epidemiological studies have found an association between diets rich in lycopene and a reduced incidence of CVD, leading to several studies to further investigate its potential cardio-protective effects. [18,19].

Hydroxytyrosol represents the major anti-atherogenic polyphenol compounds in olive oil. Epidemiological studies have reported a correlation between increased levels of olive oil in the diet and a lower risk of developing atherosclerosis, and have suggested the use of hydroxytirosol as a nutraceutical for atherosclerosis. In particular these substance have demonstrated a reduced expression of the pro-inflammatory adhesion proteins vascular cell adhesion molecule 1 (VCAM-1) and intercellular adhesion molecule 1 (ICAM-1) in human umbilical vein endothelial cells (HUVEC) [20]. Many trials have investigated the healthy benefits of hydroxytyrosol supplementation. These studies have demonstrated a decrease in the ratio of T-CHOL and increase in HDL-C, with a reduction of markers of oxidative stress [21] such as IL-6 and CRP levels [22,23], IFN- $\gamma$ [24], and ICAM-1 and monocyte number [25]. High hydroxytyrosol levels it is considered indicative of one of the major anti-atherogenic polyphenol compounds olive-oil.

Policosanol is a well-defined mixture of higher aliphatic primary alcohols isolated from sugar cane wax, with documented cholesterol-lowering effects proven for a dose range from 5-20 $\mathrm{mg} /$ day in patients with dyslipidemia [26] by increased hepatic LDL uptake and serum LDL catabolic rates, and the inhibition of hepatic cholesterol synthesis at the mevalonic acid stage of the pathway. A systematic review and meta-analysis of randomized controlled studies showed that policosanol was safe, well tolerated and effective for LDL reduction in patients with hyperlipidemia [27].

Vitamin E represent an important antioxidant considered as nutraceutical for its antioxidant and vasodilatory properties for the prevention of atherosclerosis [28]. Even if many studies have documented that vitamin $\mathrm{E}$ has not been proven to be consistently effective in long term prevention of CVD the anti-oxidative and vasodilatory properties of this vitamin are important for prevention of the atherosclerosis process.

Zinc $(\mathrm{Zn})$ is an agent with anti-oxidant, anti-inflammatory, anti-apoptotic and important activities into the regulation of lipid homeostasis. Many studies have demonstrated that zinc reduction resulted in iron overload, which thereby directly activated the conversion activity of stearoyl-CoA desaturase (SCD) with promotion of lipid biosynthesis and accumulation [29]. 


\section{Conclusions}

In this study our NC contains low doses of naturally occurring substances that exert complementary actions designed to prevent the formation of atherosclerotic plaques by significant and important lipid lowering effects after 12 treatment weeks. The important reduction of LDL-C values and inflammatory markers (h-PCR and fibrinogen) can be prevent the formation of atherosclerotic plaque, because this NC offer the opportunity to achieving significant reductions in C-LDL $(-17.73 \%)$ and T-COL $(-20.53 \%)$ levels, equivalent to what can be expected with low dose of statin therapy (lovastatin, simvastatin, pravastatin). For this reason this NC may be used in patients with mild hyperlipidemia intolerant to statin therapy, with chronic kidney disease, and liver disease.

A particular aspect of our study is represented by the low concentration of monacolin $\mathrm{K}$ (only $3 \mathrm{mg}$ ). Another important result of our study is the good safety and tolerability profile due to the intentional combination of low doses of its active ingredients. For these reasons this NC associated with dietary measurements, may be an excellent alternative for subjects with mild to moderate hyperlipidemia, in patients intolerant to statin, and for whom statins are not indicated (liver and kidney disease), and or in combination with other lipid-lowering agents in the attempt to avoid the untoward effects that are often associated with high dose pharmacological therapy.

In conclusion this new NC, in addition to dietary measures, represent an excellent alternative for subjects with mild to moderate hyperlipidemia and for all dyslipidemic patients for whom statins are not indicated. The natural compounds included in our NC may be beneficial for the prevention or treatment of atherosclerosis, because they have anti-inflammatory properties and potential beneficial effects for to reducing CV risk.

Our study has some limitations, namely a small sample size and short study duration. Further studies are required to fully evaluate the effectiveness and tolerability of this NC will lead to the identification of a novel treatment and preventive strategy in order to reduce lipid profile values and the global prevalence of CVD.

Author Contributions: Conceptualization, G.R. and N.D.; Methodology, G.R.; Investigation, MA.G.; Resources, N.D.; Data Curation, MA.G.; Writing-Original Draft Preparation, G.R. and W.C.; Writing-Review \& Editing, G.R. and N.D.; Supervision, G.R.

Conflicts of Interest: The authors declare no conflict of interest.

\section{References}

1. Perk, J.; de Backer, G.; Gohlke, H.; Graham, I.; Reiner, Ž.; Verschuren, M.; Albus, C.; Benlian, P.; Boysen, G.; Mezzani, A.; et al. European Guidelines on cardiovascular disease prevention in clinical practice (version 2012): The Fifth Joint Task Force of the European Society of Cardiology and Other Societies on Cardiovascular Disease Prevention in Clinical Practice. Eur. Heart J. 2012, 33, 635-701. [CrossRef] [PubMed]

2. Mozaffarian, D.; Benjamin, E.J.; Go, A.S.; Arnett, D.K.; Blaha, M.J.; Cushman, M.; de Ferranti, S.; Després, J.P.; Fullerton, H.J.; Howard, V.J.; et al. Heart disease and stroke statistics-2015 update: A report from the American Heart Association. Circulation 2015, 131, e29-e322. [CrossRef] [PubMed]

3. Otsuka, F.; Yasuda, S.; Noguchi, T.; Ishibashi-Ueda, H. Pathology of coronary atherosclerosis and thrombosis. Cardiovasc. Diagn. Ther. 2016, 6, 396-408. [CrossRef] [PubMed]

4. Kamal-Bahl, S.J.; Burke, T.; Watson, D.; Wentworth, C. Discontinuation of lipid modifying drugs among commercially insured United States patients in recent clinical practice. Am. J. Cardiol. 2007, 15, 530-534. [CrossRef] [PubMed]

5. Piepoli, M.F.; Hoes, A.W.; Agewall, S.; Albus, C.; Brotons, C.; Catapano, A.L.; Cooney, M.T.; Corrà, U.; Cosyns, B.; Deaton, C. ESC/EAS Guidelines for the Management of Dyslipidaemias. The Task Force for the Management of Dyslipidaemias of the European Society of Cardiology (ESC) and European Atherosclerosis Society (EAS). Developed with the special contribution of the European Association for Cardiovascular Prevention \& Rehabilitation (EACPR). Atherosclerosis 2016, 253, 281-344.

6. Yuotang, C.W.; Mousa, S.A. The effect of red yeast rice (Monascuspurpureus) in dyslipidemia and other disorders. Complement. Ther. Med. 2012, 20, 466-474. 
7. Liu, J.; Zhan, G.J.; Shi, Y.; Grimsgaard, S.; Alraek, T.; Fønnebø, V. Chinese red yeast rice (Monascuspurpureus) for primary hyperlipidemia: A meta-analysis of randomized controlled trials. Chin. Med. 2006, 23, 1-4.

8. Cameron, J.; Ranheim, T.; Kulseth, M.A.; Leren, T.P.; Laerdahl, J.K. Berberine decrease PCSK9 expression in HepG2 cells. Atherosclerosis 2008, 201, 266-273. [CrossRef] [PubMed]

9. Cheng, W.-E.; Ying Chang, M.; Wei, J.Y.; Chen, Y.J.; Maa, M.C.; Leu, T.H. Berberine reduces Toll-like receptor-mediated macrophage migration by suppression of Src enhancement. Eur. J. Pharmacol. 2015, 757, 1-10. [CrossRef] [PubMed]

10. Lee, T.-S.; Chen, C.J.; Ke, P.H.; Chiang, A.N. Anti-atherogenic effect of berberine on LXR $\alpha$-ABCA1-dependent cholesterol efflux in macrophages. J. Cell Biochem. 2010, 111, 104-110. [CrossRef] [PubMed]

11. Cicero, A.; Ertek, S. Metabolic and cardiovascular effects of berberine; from preclinical evidences to clinical trial results. J. Clin. Lipidol. 2009, 4, 553-563. [CrossRef]

12. Ghirlanda, G.; Oradei, A.; Manto, A.; Lippa, S.; Uccioli, L.; Caputo, S.; Greco, A.V.; Littarru, G.P. Evidence of plasma $\mathrm{CoQ}_{10}$-lowering effect by HMG-CoA reductase inhibitors: A double-blind, placebo-controlled study. J. Clin. Lipidol. 1993, 33, 226-229. [CrossRef]

13. Kumar, A.; Kaur, H.; Devi, P.; Mohan, V. Role of Coenzyme Q10 (CoQ10) in cardiac disease, hypertension and Meniere-like syndrome. Pharmacol. Ther. 2009, 124, 259-268. [CrossRef] [PubMed]

14. Voloshyna, I.; Hai, O.; Littlefield, M.; Carsons, S.; Reiss, A. Resveratrol mediates anti-atherogenic effects on cholesterol flux in human macrophages and endothelium via PPAR $\gamma$ and adenosine. Eur. J. Pharmacol. 2013, 698, 299-309. [CrossRef] [PubMed]

15. Richard, J.L. Coronary risk factors. The French paradox. Arch. Mal Coeur Vaiss. 1987, 80, 17-21. [PubMed]

16. Levantesi, G.; Marfisi, R.; Mozaffarian, D.; Franzosi, M.G.; Maggioni, A.; Nicolosi, G.L.; Schweiger, C.; Silletta, M.; Tavazzi, L.; Tognoni, G.; et al. Wine consumption and risk of cardiovascular events after myocardial infarction: Results from the GISSI-Prevenzione trial. Int. J. Cardiol. 2013, 163, 282-287. [CrossRef] [PubMed]

17. Fuhrman, B.; Elis, A.; Aviram, M. Hypercholesterolemic effect of lycopene and $\beta$-carotene is related to suppression of cholesterol synthesis and augmentation of LDL receptor activity in macrophage. Biochem. Biophys. Res. Commun. 1997, 233, 658-662. [CrossRef] [PubMed]

18. Arab, L.; Steck, S. Lycopene and cardiovascular disease. Am. J. Clin. Nutr. 2000, 71, 1691-1695. [CrossRef] [PubMed]

19. Rao, A.V.; Agarwal, S. Role of antioxidant lycopene in cancer and heart disease. J. Am. Coll. Nutr. 2000, 19, 563-569. [CrossRef] [PubMed]

20. Dell'Agli, M.; Fagnani, R.; Mitro, N.; Scurati, S.; Masciadri, M.; Mussoni, L.; Galli, G.V.; Bosisio, E.; Crestani, M.; De Fabiani, E.; et al. Minor components of olive oil modulate pro-atherogenic adhesion molecules involved in endothelial activation. J. Agric. Food Chem. 2006, 54, 3259-3264. [CrossRef] [PubMed]

21. Fito, M.; Cladellas, M.; de la Torre, R.; Martí, J.; Alcántara, M.; Pujadas-Bastardes, M.; Marrugat, J.; Bruguera, J.; López-Sabater, M.C.; Vila, J.; et al. members of the SOLOS Investigators. Antioxidant effect of virgin olive oil in patients with stable coronary heart disease: a randomized, crossover, controlled, clinical trial. Atherosclerosis 2005, 181, 149-158. [CrossRef] [PubMed]

22. Carluccio, M.A.; Siculella, L.; Ancora, M.A.; Massaro, M.; Scoditti, E.; Storelli, C.; Visioli, F.; Distante, A.; De Caterina, R. Olive oil and red wine antioxidant polyphenols inhibit endothelial activation: Antiatherogenic properties of mediterranean diet phytochemicals. Arterioscler. Thromb. Vasc. Biol. 2003, 23, 622-629. [CrossRef] [PubMed]

23. Scoditti, E.; Calabriso, N.; Massaro, M.; Pellegrino, M.; Storelli, C.; Martines, G.; De Caterina, R.; Carluccio, M.A. Mediterranean diet polyphenols reduce inflammatory angiogenesis through MMP-9 and COX-2 inhibition in human vascular endothelial cells: A potentially protective mechanism in atherosclerotic vascular disease and cancer. Arch. Biochem. Biophys. 2012, 527, 81-89. [CrossRef] [PubMed]

24. Rosignoli, P.; Fuccelli, R.; Fabiani, R.; Servili, M.; Morozzi, G. Effect of olive oil phenols on the production of inflammatory mediators in freshly isolated human monocytes. J. Nutr. Biochem. 2013, 24, 1513-1519. [CrossRef] [PubMed]

25. Valls, R.-M.; Farràs, M.; Suárez, M.; Fernández-Castillejo, S.; Fitó, M.; Konstantinidou, V.; Fuentes, F.; López-Miranda, J.; Giralt, M.; Covas, M.I.; et al. Effects of functional olive oil enriched with its own phenolic compounds on endothelial function in hypertensive patients. A randomised controlled trial. Food Chem. 2015, 167, 30-35. [CrossRef] [PubMed] 
26. Gouni-Berthold, I.; Berthold, H.K. Policosanol: Clinical pharmacology and therapeutic significance of a new lipid-lowering agent. Am. Heart J. 2002, 143, 356-365. [CrossRef] [PubMed]

27. Chen, J.T.; Wesley, R.; Shamburek, R.D.; Pucino, F.; Csako, G. Meta-analysis of natural therapies for hyperlipidemia: Plant sterols and stanols versus policosanol. Pharmacotherapy 2005, 25, 171-183. [CrossRef] [PubMed]

28. Riccioni, G.; D'Orazio, N.; Salvatore, C.; Franceschelli, S.; Pesce, M.; Speranza, L. Carotenoids and vitamins $\mathrm{C}$ and $\mathrm{E}$ in the prevention of cardiovascular disease. Int. J. Vitam. Nutr. Res. 2012, 82, 15-26. [CrossRef] [PubMed]

29. Kheirouri, S.; Alizadeh, M.; Maleki, V. Zinc against advanced glycation end products. Clin. Exp. Pharmacol. Physiol. 2017, 8, 1440-1460. [CrossRef] [PubMed]

Sample Availability: Samples of the compounds are not available from the authors.

(C) 2018 by the authors. Licensee MDPI, Basel, Switzerland. This article is an open access article distributed under the terms and conditions of the Creative Commons Attribution (CC BY) license (http://creativecommons.org/licenses/by/4.0/). 